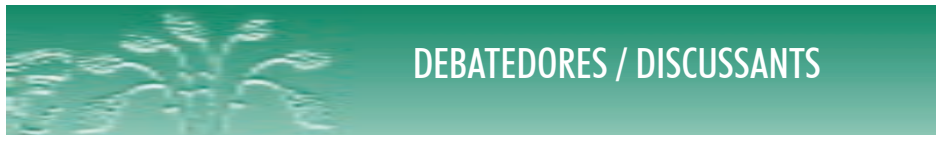

DOI: http://dx.doi.org/10.12957/demetra.2014.11749

\title{
Judicialização da saúde e democracia
}

\section{Judicialization of health and democracy}

Ligia Bahia'

1 Instituto de Saúde Coletiva, Universidade Federal do Rio de Janeiro. Rio de Janeiro, RJ, Brasil.

Correspondência / Correspondence Lígia Bahia

E-mail: ligiabahia55@gmail.com
Na área de Saúde Coletiva, o fenômeno da "judicialização da saúde" emergiu e foi imediatamente interpretado como uma ameaça à equidade, como uma oposição entre individual e coletivo, ricos e pobres e não tensão, conflito entre direito e direitos. A produção científica disponível sobre a temática, em geral, parte de pressupostos, quase sempre implícitos, sobre os danos causados ao Sistema Único de Saúde (SUS) de uma também suposta intervenção acrítica (não técnica) do Poder Judiciário. Os autores dos trabalhos procuraram demonstrar que as demandas judiciais tendem a prejudicar uma divisão de recursos mais racional baseada em critérios epidemiológicoclínicos, e não na exigibilidade do direito subjetivo.

$\mathrm{O}$ artigo "Perfil das demandas judiciais para o fornecimento de fórmulas nutricionais encaminhadas ao Ministério da Saúde" pertence a essa florada de investigações, baseadas na díade judicialização-iniquidade. Seu principal mérito é, ao jogar luzes sobre as restrições de coberturas e estratégias de acesso a alimentos muito caros que são insumos estratégicos à manutenção da vida de segmentos específicos de crianças e adultos, abrir uma avenida à reflexão sobre as interfaces entre as tecnologias existentes e alternativas terapêuticas ao reafirmar a relevância da nutrição para a saúde. Adicionalmente, o estudo contribui para dimensionar o perímetro das demandas judiciais: as solicitações se originaram de apenas 63 municípios, 
e entre estes especialmente cinco concentraram parcela expressiva dos processos recebidos pelo Ministério da Saúde em 2013.

Limites do estudo são devidamente assinalados pelo(s) autor(es). Os problemas de abrangência e qualidade dos dados limitam inferências. A unidade de observação ser o processo de acolhida (embora sem que saiba o resultado em termos de cobertura efetiva) pelo Ministério da Saúde, e não as demandas apresentadas ao Judiciário que impedem estimativas sobre o universo das demandas judiciais por fórmulas nutricionais, na medida em que estados e municípios também são acionados, o que coíbe quaisquer estimativas. A ausência de registro nos processos sobre o atendimento ou não das tutelas tampouco admite ilações definitivas sobre a natureza irracional (especialmente aquelas que chamaram a atenção dos autores: solicitações sem diagnóstico) dessas demandas.

Tais obstáculos de caráter procedimental poderão ser superados tanto pelos esforços do Poder Judiciário, de dar publicidade e acessibilidade à tramitação dos processos, quanto pela melhoria dos registros sobre demandas judiciais dos órgãos executivos da Saúde, inclusive aqueles que se tornaram referência para as decisões do Ministério Público e instâncias do Poder Judiciário.

Portanto, o debate a ser enfrentado não é sobre o conteúdo e forma do artigo, e sim sobre a necessidade de aprofundar o conhecimento sobre as relações entre os denominados poderes republicanos (Executivo, Legislativo e Judiciário) e assim avançar na compreensão sobre as lógicas subjacentes à emissão de normas, tanto pelo Ministério da Saúde quanto pelo Poder Judiciário. Considerar que a normatividade dos órgãos governamentais da saúde é exclusivamente informada por critérios "técnicos" e que a dos demais poderes é leiga e sujeita à captura por interesses privados é no mínimo ingênuo e compõe um modelo explicativo no qual a Saúde é vitima ora do Judiciário, ora do Legislativo. Essa oposição entre a "boa" norma e a "má" norma pública (a oposição entre órgãos governamentais) auxilia o ocultamento das reais tensões e conflitos. Afinal de contas, o que é que está se discutindo no que diz respeito à equidade, quando o próprio artigo menciona, sem detalhar, que as coberturas do SUS variam entre estados e municípios?

A projeção do Poder Judiciário e o obscurecimento das instituições tradicionalmente especializadas na política (parlamento) não derivam ambições descabidas de um conjunto de magistrados. O segundo pós-guerra demarca mudanças no que se refere à penalização de agentes estatais que violam direitos humanos, e o maior exemplo é o Tribunal de Nuremberg, que julgou crimes dos dirigentes nazistas. Mas da guerra vieram também os estímulos para que as constituições explicitassem valores fundamentais a serem preservados pelos Estados soberanos (o denominado constitucionalismo democrático) e o Welfare State, com suas pretensões de organizar o capitalismo e promover relações harmoniosas entre as classes sociais, trazendo o direito para o centro da vida social. ${ }^{1}$ 
Por sua vez, a legislação do welfare, intrinsecamente indeterminada e incorporando aspectos materiais, questionou a pureza formal do direito na ortodoxia liberal. As controvérsias sobre sua interpretação dos direitos em casos concretos aduziu às atribuições dos juízes a legislação implícita por meio da emissão de normas que ampliam a presença do Poder Judiciário na vida pública. No Brasil, a Constituição de 1988 estabeleceu as bases para a expansão da regulação jurídica das relações sociais. O neoliberalismo, que retorna a questionar direitos trabalhistas e sociais em sua defesa do Estado mínimo, erode o papel de coesão dos sindicatos e associações e contraditoriamente estimula a busca de consumidores/cidadãos de forma fragmentada a um Poder Judiciário que justifica suas decisões com base nos direitos constitucionais.

Os poderes Legislativo, Executivo e Judiciário têm como atribuição estabelecer forma e conteúdo às indeterminações dos direitos sociais enunciados. Evidentemente, os processos de definição e redefinição de normas de acesso a ações a serviços de saúde não são lineares e nem desprovidos de ambiguidades. Os conflitos de interesses, os lobbies, estão presentes na vida social. Embora cada instituição pública possua barreiras específicas (técnicas) para conter as "invasões" de agentes e racionalidades alheios a suas burocracias, não existem regras isentas, neutras. Há sempre várias justificativas para fundamentar decisões e é preciso entender que essas também são arenas de disputa. ${ }^{2}$

Portanto, a hipótese (não explicitada) de que o Judiciário é uma instância ilegítima, porque não detém expertise técnica para normatizar coberturas do SUS, é um bom fio condutor mas requer consultas à literatura sobre o tema para afastar o risco de destituir os significados políticos do conceito de técnica. As instituições de saúde só cumprirão melhor as atribuições de filtragem de necessidades e demandas se e somente se forem capazes de ampliar as coberturas e se apresentarem como nucleares nos processos de inovação e oferta de opções preventivas, diagnósticas e terapêuticas.

A "vantagem comparativa" da saúde sobre os órgãos do Poder Judiciário seria exatamente a oferta de um cardápio personalizado, a ser constantemente ajustado, enquanto que a demanda judicial se refere a um ou mais itens a serem consumidos/utilizados de maneira independente da evolução do caso. Paradoxalmente, a justiça "eterniza” prescrições/medicações que seriam emergenciais, como também se desresponsabiliza por eventuais sequelas causadas por indicações inapropriadas, bloqueando a iniciativa e criatividade dos serviços de saúde. No entanto, o protagonismo da Saúde não pode ser exercido em um contexto de racionamento acentuado de recursos assistenciais.

Demandas sociais podem e devem ser direcionadas a diversos órgãos e requerem um debate acadêmico aprofundado para evitar a naturalização de determinada distribuição de poder entre grupos e forma de mediar a relação entre Estado e sociedade. A Constituição Federal de 1988, a 
mesma que promulgou o SUS, recriou o Ministério Público, a quem incumbiu a defesa da ordem jurídica, do regime democrático e dos interesses sociais e individuais indisponíveis. É preciso, inclusive, reconhecer posicionamentos incompatíveis e incongruentes, como por exemplo, o fato de estudiosos que acentuam a carência de conhecimento técnico do Judiciário a ele recorrerem para resolver problemas de coberturas e preços de seus planos privados de saúde, para não reduzir o debate a um conjunto de evidências descontextualizadas.

Seria impossível abordar todos esses elementos no âmbito de um artigo. O ponto precípuo do debate sobre a judicialização da saúde não é a abdicação das normas técnicas, mas sim a necessidade de reconhecer que essas regras não são neutras e que a existência de um código próprio não deve encobrir a descrição e análise de conflitos. A aproximação realista das tensões sociais é o caminho adequado para encontrar alternativas institucionais para o regramento democrático do acesso à saúde.

\section{Referências}

1. Vianna LW, Burgos MB, Salles PM. Dezessete anos de judicialização da política. Tempo Social, Revista de Sociologia da USP 2007; 19(2):39-85.

2. Nobre M, Rodriguez JR. Judicialização da política: déficits explicativos e bloqueios normativistas. Novos Estudos 2011; 91:5-20. 